\title{
Basal Cell Carcinoma or Trichoblastoma? Dermoscopic Examination of Black Macules Developing in the Same Nevus Sebaceus
}

\author{
Shinya Kitamura Hiroo Hata Keisuke Imafuku Hiroshi Shimizu \\ Department of Dermatology, Hokkaido University Graduate School of Medicine, Sapporo, \\ Japan
}

\section{Key Words}

Nevus sebaceus - Basal cell carcinoma - Trichoblastoma - Dermoscopy

\begin{abstract}
Nevus sebaceus (NS) is a common congenital birthmark, and various tumors have been reported to develop in NS. Basal cell carcinoma (BCC) seldom occurs in NS, and it is very important to be able to clinicopathologically distinguish $B C C$ from trichoblastoma. Herein, we describe a case of BCC and trichoblastoma occurring simultaneously in the same NS, including the differential dermoscopic features. BCC is clinically difficult to distinguish from trichoblastoma because the clinical manifestations are similar. In a dermoscopic examination of $B C C$, arborizing vessels are one of the diagnostically significant features. In our case, the BCC showed 'multiple' black structures, and the trichoblastoma showed a 'single' black structure without arborizing vessels. To the best of our knowledge, there have been no reports on the dermoscopic findings of secondary tumors on NS.

(C) 2016 The Author(s)

Published by S. Karger AG, Basel
\end{abstract}

\section{Introduction}

Nevus sebaceus (NS) is a common congenital birthmark that occurs most frequently on the head and face. Removal is preferable because various tumors have been reported to develop in NS [1,2]. Basal cell carcinoma (BCC) seldom occurs in NS, and it is very important to

\section{KARGER}

Hiroo Hata, MD, PhD

Department of Dermatology

Hokkaido University Graduate School of Medicine

N15 W7, Kita-ku, Sapporo 060-8638 (Japan)

E-Mail hata07jp@yahoo.co.jp 
Kitamura et al.: Basal Cell Carcinoma or Trichoblastoma? Dermoscopic Examination of Black Macules Developing in the Same Nevus Sebaceus

be able to clinicopathologically distinguish BCC from trichoblastoma. Herein, we describe a case of BCC and trichoblastoma occurring simultaneously in the same NS, including the differential dermoscopic features.

\section{Case Report}

A 77-year-old woman had been diagnosed at the age of 15 years with NS which had started from the left side of her ear and extended to her chest. Her case was followed up after she had presented at a dermatologic clinic. She was referred to our hospital with a 3year history of black macules on the left ear. She had undergone surgical excision for BCC on the left cheek 2 years before. A physical examination showed yellowish plaques around the left side of the neck and small, numerous yellow papules in the NS. A black macule of $2 \mathrm{~mm}$ in diameter was observed on the left auricle (fig. 1a, arrowhead). A dermoscopic examination revealed multiple blue-gray ovoid nests and whitish veils, but arborizing vessels were not found (fig. 1b). A surgical specimen showed that tumor cells were proliferating from the epidermis to the upper dermis and were arranged in a palisading pattern at the periphery with basal melanosis. Deposits of mucin and clefts were observed in the surrounding area with dilated vessels in the papillary dermis (fig. 1c, d). Based on these histological features, the macule was diagnosed as BCC. After surgical removal, no recurrence was observed.

Three months after the surgery, a small black macule appeared on the left earlobe which slowly enlarged. A physical examination indicated the presence of a small black macule with a diameter of $1 \mathrm{~mm}$ on the left earlobe (fig. 2a, arrowhead). A dermoscopic examination revealed a round, homogeneous, brownish structure without arborizing vessels (fig. $2 \mathrm{~b}$ ). We performed an excisional biopsy. Histopathologically, the surgical specimen showed that the tumor cells were proliferating in the dermis, presented as multiple different shapes, were either clear or basophilic, and were arranged in a partial palisading pattern. The tumor cells also resembled follicular germinative cells without keratinizing cysts, and islands of tumor cells were present as hair bulbs surrounding fibrous stroma (fig. 2c, d). The macule was given the final diagnosis of trichoblastoma.

\section{Discussion}

BCC is clinically difficult to distinguish from trichoblastoma because the clinical manifestations are similar. A study on tumors occurring in NS found that trichoblastoma was observed in $4.7 \%$ of cases ( 28 of 596 cases) and BCC in $0.8 \%$ of cases (5 of 596 cases) [3]. In a dermoscopic examination of BCC, arborizing vessels were observed in $84.1 \%$ of cases and multiple blue-gray ovoid nests in $36 \%$ of cases [4]. Therefore, arborizing vessels are a diagnostically significant feature.

In our case, the BCC showed 'multiple' black structures, and the trichoblastoma showed a 'single' black structure without arborizing vessels. We theorize that this difference is a specific clue when distinguishing between BCC and trichoblastoma in NS. In a dermoscopic examination of NS, it is difficult to precisely evaluate a macule with vessels directly under the epidermis due to histopathological modifications of the background, particularly under the influence of epidermal proliferation. This is why our BCC did not reveal arborizing vessels. 
Kitamura et al.: Basal Cell Carcinoma or Trichoblastoma? Dermoscopic Examination of Black Macules Developing in the Same Nevus Sebaceus

In conclusion, most NS are removed to avoid secondary tumors, including BCC; thus, there have been no reports on their dermoscopic findings. It is noteworthy that we demonstrate the dermoscopic features of BCC developing in NS.

\section{Acknowledgement}

The authors appreciate the pathological advice given by Masanobu Kumakiri, MD, PhD.

\section{Statement of Ethics}

The authors have no ethical conflicts to disclose.

\section{Disclosure Statement}

The authors declare that they have no conflicts of interest.

\section{References}

1 Prioleau PG, Santa Cruz DJ: Sebaceous gland neoplasia. J Cutan Pathol 1984;11:396-414.

2 Jones EW, Heyl T: Naevus sebaceus. A report of 140 cases with special regard to the development of secondary malignant tumours. Br J Dermatol 1970;82:99-117.

3 Cribier B, Scrivener Y, Grosshans E: Tumors arising in nevus sebaceus: a study of 596 cases. J Am Acad Dermatol 2000;42:263-268.

4 Popadic M: Statistical evaluation of dermoscopic features in basal cell carcinomas. Dermatol Surg 2014;7:18-24. 


\section{Case Reports in Oncology}
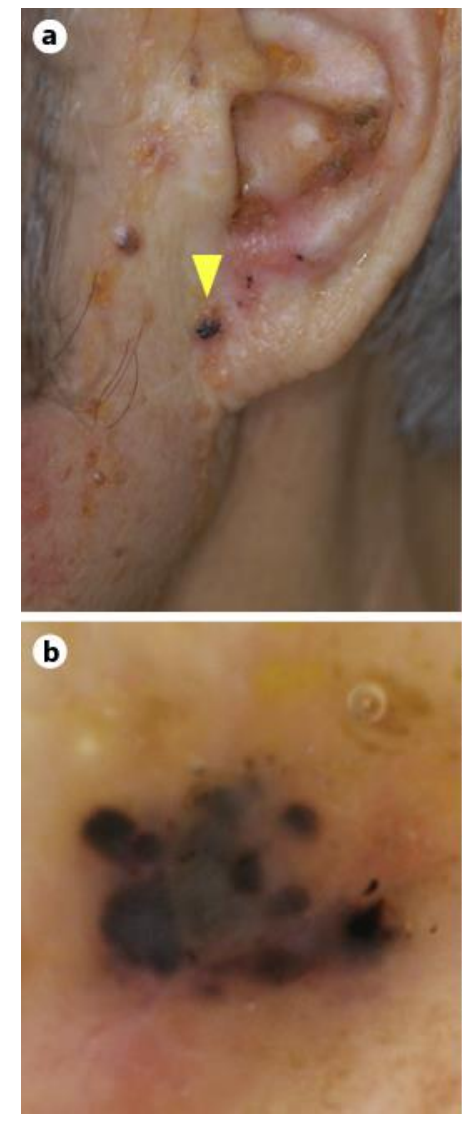

\begin{tabular}{l|l}
\hline Case Rep Oncol 2016;9:143-147 \\
\hline DOI: $10.1159 / 000443162$ & $\begin{array}{l}\text { (c) 2016 The Author(s). Published by S. Karger AG, Basel } \\
\text { www.karger.com/cro }\end{array}$ \\
\hline
\end{tabular}

Kitamura et al.: Basal Cell Carcinoma or Trichoblastoma? Dermoscopic Examination of Black Macules Developing in the Same Nevus Sebaceus
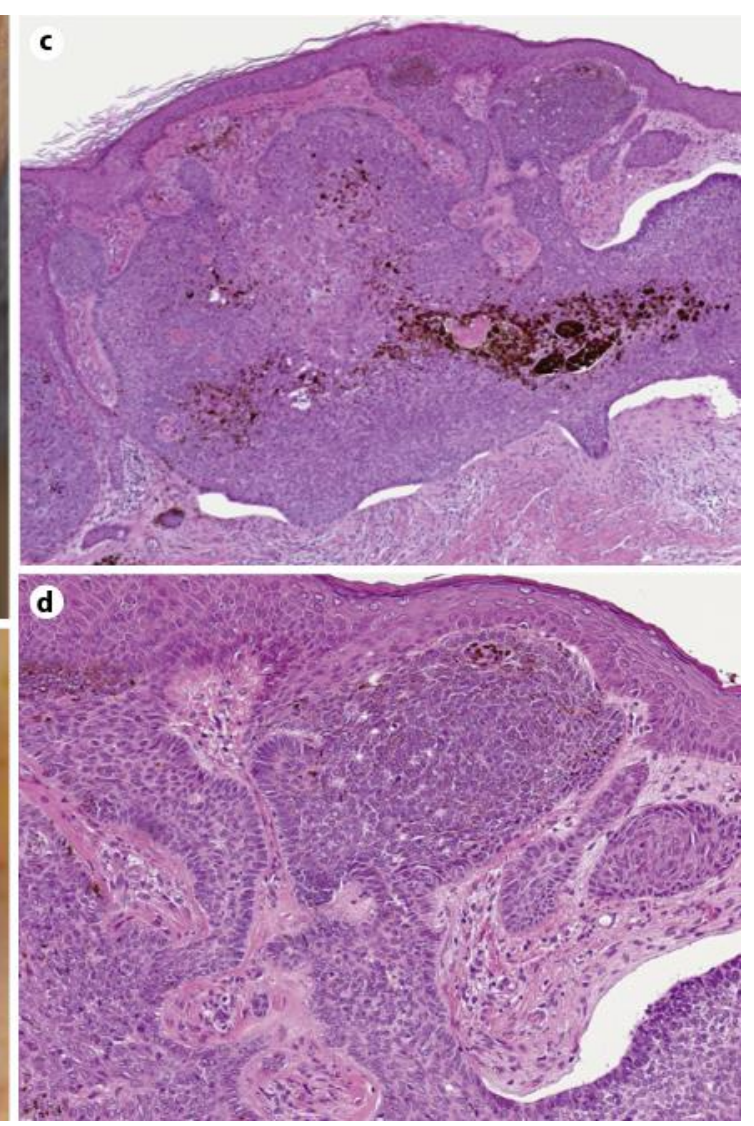

Fig. 1. The clinical, dermoscopic, and histopathological manifestations of BCC. a A black macule of $2 \mathrm{~mm}$ in diameter is observed on the left auricle (arrowhead). b Dermoscopic findings: multiple blue-gray ovoid nests and a whitish veil are observed, without arborizing vessels. c, $\mathbf{d}$ The tumor cells proliferate in a palisading pattern at the periphery, with basal melanosis. There are deposits of mucin and clefts in the surrounding area. The upper dermis shows the infiltration of inflammatory cells, mainly lymphocytes [HE; original magnification: $\times 40(\mathrm{c}), \times 100(\mathrm{~d})]$. 


\section{Case Reports in Oncology}

\begin{tabular}{l|l}
\hline Case Rep Oncol 2016;9:143-147 \\
\hline DOI: 10.1159/000443162 & $\begin{array}{l}\text { (c) 2016 The Author(s). Published by S. Karger AG, Basel } \\
\text { www.karger.com/cro }\end{array}$ \\
\hline
\end{tabular}

Kitamura et al.: Basal Cell Carcinoma or Trichoblastoma? Dermoscopic Examination of Black Macules Developing in the Same Nevus Sebaceus
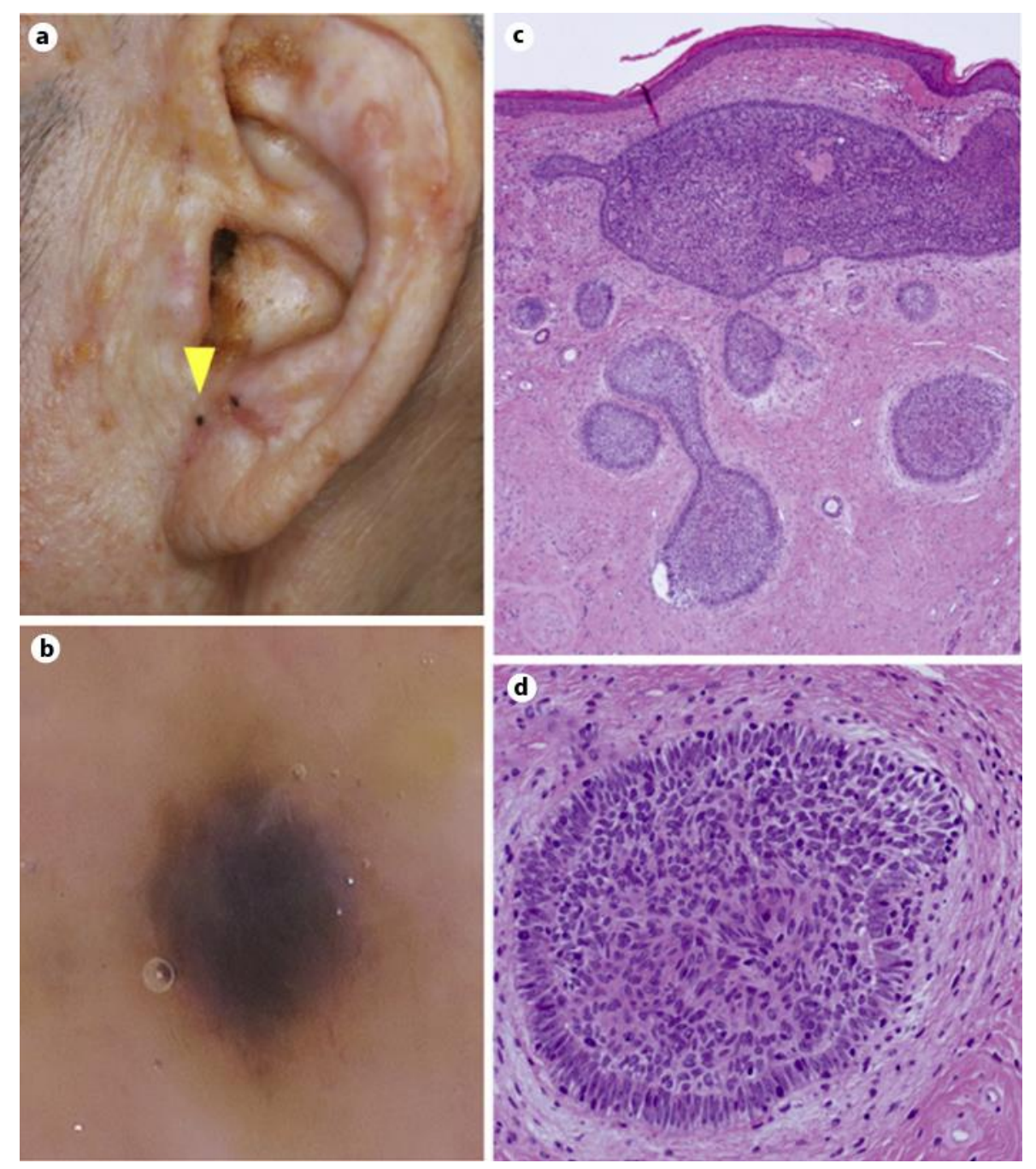

Fig. 2. Clinical and histopathological manifestations of trichoblastoma. a A small black macule of $1 \mathrm{~mm}$ in diameter is observed on the left earlobe (arrowhead). b Dermoscopic findings: a round, homogeneous brownish structure is observed, without arborizing vessels. c The tumor cells proliferate in the dermis, with the cells being of multiple shapes, clear or basophilic and arranged in a partial palisading pattern (HE; original magnification: $\times 40$ ). $\mathbf{d}$ The tumor cells resemble a hair bulb surrounding fibrous stroma (HE; original magnification: $\times 100$ ). 